\title{
Analysis of Methane-Hydrate-Bearing Formation using Well Logging and VSP Data in the MITI Nankai-Trough Wells, Japan
}

\author{
Yoshinori Sanada ${ }^{1)}$, Tokujiro Takayama ${ }^{2)}$, Masatoshi Nishi ${ }^{3)}$, Hiroaki Yamamoto ${ }^{3)}$, Shigemi Matsuda ${ }^{3)}$ \\ and Takashi Uchida ${ }^{2)}$ \\ 1) Dept. of Earth Resources Engineering, Kyoto University, Kyoto, 606-8501, Japan. \\ 2) JAPEX Research Center, Japan Petroleum Exploration Company, Ltd., 1-2-1 Hamada, Mihama-ku, \\ Chiba 261-0025, Japan \\ 3) Schlumberger K.K. 7th Floor, House Hamamatsucho Bldg., 2-7-1, Hamamatsucho, Minato-ku,
} Tokyo 105-0013, Japan

\begin{abstract}
In this project, logging data showed P-wave low-velocity layers below bottom edge of methane-hydrate-bearing formation. Sonic $\log$ (DSI) couldn't acquire accurate compressional velocity in this zone, thus accurate correlation couldn't be taken between logging, VSP and surface seismic map. Small amount of gas concentration was presumed to cause difficulty of getting P-wave low-velocity. VSP interval velocity was used to compensate this low-velocity layer, and it showed slower value than mud velocity. Synthetic seismogram was created by VSP-compensated velocity to compare against corridor stack of VSP. As a result, the depths above and below methane-hydrate-bearing formation were correlated well with Synthetic seismogram and reflectivity events of VSP. By using this correlation technique, distribution of methane-hydrate-bearing formation can be estimated well.
\end{abstract}

\section{Introduction}

MITI Nankai-trough wells were planned for exploration of methane-hydrate-bearing formation over BSR observed area, offshore Tenryu-river, Shizuoka-prefecture (JNOC, 2000). BSR was reflection event on surface seismic map to imply the concentration of methane-hydrate. BSR was widely observed around $500-1500 \mathrm{~m}$ under the sea level. In drilling project, total 6 wells were drilled. The water depth was $945 \mathrm{~m}$, and total drilling depth was $1300 \mathrm{~m}$. Continuous coring was conducted between $1175-1254 \mathrm{~m}$, where methane-hydrate-bearing formation was expected. Recovered cores showed anomaly of low temperature and low salinity of pore fluid. Methane-hydrate was found to form as pore-space hydrate, which cemented pores between sand grains.

Resistivity (HALS), Sonic (DSI), NMR and FMI logging were performed to evaluate the depth and distribution of methane-hydrate-bearing formation. Also zero-offset VSP was performed to correlate with BSR, which was shown on surface seismic map.

Methane-hydrate saturation reached $80 \%$ as maximum, according to core analysis and logging analysis (JNOC, 2000 ; Tezuka et al., 2000 ; Akihisa et al., 2002). Intervals between 1182-1188m and $1203-1212 \mathrm{~m}$ were expected as methane-hydrate-bearing formation by high resistivity image of FMI logging. Significant decreases of compressional energy were observed around bottom of methane-hydrate-bearing formation (1200-1221m) and below in this zone (1237-1244m). In these 
zones, standard processing and analysis of DSI data couldn't show accurate compressional velocity, thus the correlation was not done between wireline logging, VSP and surface seismic map.

Purpose of this paper was to analyze the cause of $\mathrm{P}$-wave low-velocity anomaly, shown in the well and to identify accurate top and bottom depth of each methane-hydrate-bearing formation by using VSP-compensated synthetic seismogram and reflection event of VSP.

\section{Analysis of sonic logging and their dispersion character}

DSI could not obtain P-wave velocities below the methane-hydrate-bearing formation with standard measurements and waveform processing on DSI logging recorded in Nankai-trougth wells. In order to analyze P-waves in P-wave low-velocity formation, we processed with high frequency monopole source mode (MSP mode) and dipole source mode (LDP mode and UDP mode). The right column in Figure 1 shows VDL display between $1177-1246 \mathrm{~m}$ processed with MPS mode. There are some depths where P-head-waves are missed or the amplitudes are very weak. Between $1177 \mathrm{~m}$ and $1246 \mathrm{~m}$, there are a few intervals where P-wave arrival does not exist or its amplitude is very weak. (Zone1) $1182-1187 \mathrm{~m}: \mathrm{P}$ wave exists. (Zone2) 1200-1212m : P wave exists in the upper zone, but not visible before fluid arrival in the lower zone. (Zone3) $1215-1221 \mathrm{~m}: \mathrm{P}$ wave does not exist before fluid arrival. (Zone4) $1237-1244 \mathrm{~m}: \mathrm{P}$ wave does not exist before fluid arrival.

A little gas is detected around at $1177-1246 \mathrm{~m}$ in the hole $10 \mathrm{~m}$-far from this well, and particularly a lot of gas is observed at $1204-1207 \mathrm{~m}$. Methane-hydrate-bearing formation is indicated at 1182-1188 $\mathrm{m}$ and 1203-1212 $\mathrm{m}$ from FMI image and other log interpretation in the well. And $\mathrm{P}$-wave velocities are particularly reduced in $1237-1244 \mathrm{~m}$ below the methane-hydrate stability zone.

In dispersion curves of Figure 2, P-wave velocities were plotted against various frequencies. The horizontal axis is frequency and the vertical axis is slowness. Velocity varies with different frequencies, indicating the character of velocity dispersion. Fluid arrivals, which travel directly in the mud at the fluid velocity, are shown in $5-15 \mathrm{kHz}$ at $1238.1 \mathrm{~m}$ in P-wave low-velocity layer. But it is impossible to identify P-head-waves nor dipole-compressional arrivals in the duration. P-head-waves are identified around $157 \mathrm{us} / \mathrm{ft}$ between $10 \mathrm{kHz}$ and $15 \mathrm{kHz}$ at $1258.21 \mathrm{~m}$, which is not P-wave low-velocity layer. The leaky mode is shown between $2.5 \mathrm{kHz}$ and $15 \mathrm{kHz}$. The dipole-compressional arrivals are identified between $5 \mathrm{kHz}$ and $11 \mathrm{kHz}$. The dipole-compressional-velocities between $5 \mathrm{kHz}$ and $6.5 \mathrm{kHz}$ are same as P-head-wave velocity. But the velocities in higher frequency range are slower than P-head-wave velocities.

According to analysis above, no P-wave arrival was identified from the MPS mode waveforms on the P-wave low-velocity layers in neither time domain nor velocity-frequency domain. The reason was that $\mathrm{P}$-wave velocities in these layers will be slower than mud velocity. Biot's simulation for the porous medium module shows that $\mathrm{P}$-wave velocity can be less than $200 \mathrm{us} / \mathrm{ft}$ in unconsolidated formation under the sea bed when a little gas is concentrated in pores (Wu et al., 
1995 ). When P-wave velocity is slower than mud velocity, P-wave as a critical refraction wave can not exist in the borehole. P-wave loses its most energy while traveling in the formation. Its adjoint $\mathrm{P}$-waves are traveled in the borehole. It is difficult to measure $\mathrm{P}$-wave which travels in the slower-velocity layers than that of mud velocity because of strong fluid mode appears in the borehole, when DSI source is high frequency monopole mode. On the other hand, it is possible to measure P-wave if DSI source is low frequency monopole mode, because no fluid mode can exist under lower frequency than particular value (Pallet and Chang, 1991).

\section{3. $P$-wave velocity estimation from DSI log and VSP inversion}

The black lines on the fourth and sixth column in Figure 1 shows the slowness-time-coherence $\log$ between 1190-1270 m with monopole mode in the well. The red and blue in the background color indicates high and low coherence. "Very Slow" for Formation type and "210us/ft "for Mud slowness are selected as parameters of velocity analysis.

VSP velocity inversion method is to calculate optimum interval velocities from Check shot transit time. Figure 3 shows the VSP interval velocities and corrected sonic curve. The sonic curve is corrected with VSP velocities. Figure 4 shows original and corrected sonic curves. Drift curve indicates the difference between sonic and VSP velocity. A new acoustic impedance was calculated with corrected compressional velocity and $1.0 \mathrm{~g} / \mathrm{cc}$ density value.

Depth-time conversion table is obtained from VSP check shots. The table converts logging curves in depth into those in time. The logging curves during 1.5-1.6 sec converted to two-way time and the synthetic seismogram with $80 \mathrm{~Hz}$ Ricker wavelet are shown in Figure 5. The arrows in the figure indicate the depth of upper boundaries of methane-hydrate-bearing formation identified in the depth scale.

\section{Discussion}

Very high attenuations are observed in $1215-1221 \mathrm{~m}$ and $1237-1244 \mathrm{~m}$ in the well. Based on attenuation of DSI P-wave energy and VSP-compensated P-wave velocity, P-wave velocities in these intervals are slower than the mud velocity. It results from a little volume of gas concentration in the formation.

The bottom of methane-hydrate-bearing formation in the well was identified at $1212 \mathrm{~m}$. The P-wave low-velocity layer in $1215-1221 \mathrm{~m}$ is located right below the bottom of methane-hydrate-bearing formation. BSR was identified about $27 \mathrm{~m}$ deeper than the bottom of methane-hydrate-bearing formation. The depth of BSR was harmonic with P-wave low-velocity layer at $1237-1244 \mathrm{~m}$, which considered as gas-bearing formation. Therefore the P-wave low-velocity layers in the well were located the bottom of methane-hydrate-bearing formation and BSR appearance layer recorded on the surface seismic profiles. Consequently followings can be considered; 1) the gases concentrated in $1215-1221 \mathrm{~m}$ are trapped under the methane-hydrate-bearing formation. 2) the gas-bearing formation in $1237-1244 \mathrm{~m}$ would be cause of BSR appearance on the surface seismic profiles. 
As shown in this paper, it is difficult to obtain precise P-wave velocity in the gas-bearing formation. This is because P-wave velocity and mud velocity are overlapped or small P-wave amplitudes are hidden behind the big amplitudes of mud arrivals. In addition, it is predicted that methane-hydrate-bearing formation and gas-bearing formation are composed of unconsolidated sediments. In such formation, it would be possible that $\mathrm{P}$-wave velocities are measured with the low frequency monopole mode. And more attention on logging operation; proper centerizing, stand-off and position of sonde than usual would lead to measure better signals and improve signal-to-noise ratio.

\section{Conclusion}

P-wave low-velocity anomalies were observed at bottom of methane-hydrate-bearing formation and BSR appearance layer. Cause of slow velocity anomaly on compressional wave, observed in the MITI Nankai-trough wells, was due to small amount of gas-concentrated formation. Low-frequency-monopole measurement was required to get such $\mathrm{P}$-wave low-velocity information. Net thickness of methane-hydrate-bearing formation from logging analysis was well correlated with synthetic seismogram and reflection event of VSP. To extend these correlations, distribution area of methane-hydrate-bearing formation will be expected in 3D direction.

Acknowledgement: The authors are indebted to the research program by the Research Consortium of Methane-Hydrate Exploration in Japan. We are also grateful to all colleagues who participated with us on the project. This work was supported by the Japan National Oil Corporation (JNOC).

\section{References}

Akihisa, K., Tezuka, K., Senoh, O., and Uchida, T. (2002) Well log evaluation of gas hydrate saturation in the MITI-Nankai-Trough well, offshore south-east Japan, SPWLA 43rd Annual Logging Symposium, Oiso, Japan, Paper BB.

Japan National Oil Corporation (JNOC). (2000) The Drilling Report on MITI Test Well "Nankai-Trough" for Fundamental Exploration of Oil and Gas Resources in Japan (Internal Report).

Pallet, F.L., and Chang, C.H. (1991) Acoustic waves in borehole, CRC Press Inc, ISBN 0-8493-8890-2.

Takayama, T., Nishi, M., Yamamoto, H., Sanada, Y., Matsuda, S., and Uchida, T. (2004) Properties Clarification of P-Wave Low-Velocity Layers and Identification of Methane-Hydrate-Bearing Formation in the MITI Nankai-Trough Wells, Offshore Tokai-Oki, Japan, Resource Geology, Special Publication, V.54 (in Press).

Tezuka, K., Uchida, T., and Akihisa, K. (2000) Well Log evaluation of Gas Hydrate Saturation in the MITI Nankai Trough Well Drilled Offshore Tokai, Japan, Western Pacific Geophysics 
Meeting, Tokyo, Japan, OS21A-09

Wu Peter, T., Darling, H., and Scheibner, D. (1995) Low frequency P-wave logging for improved compressional velocity in slow gas zone, SEG Internal Report.

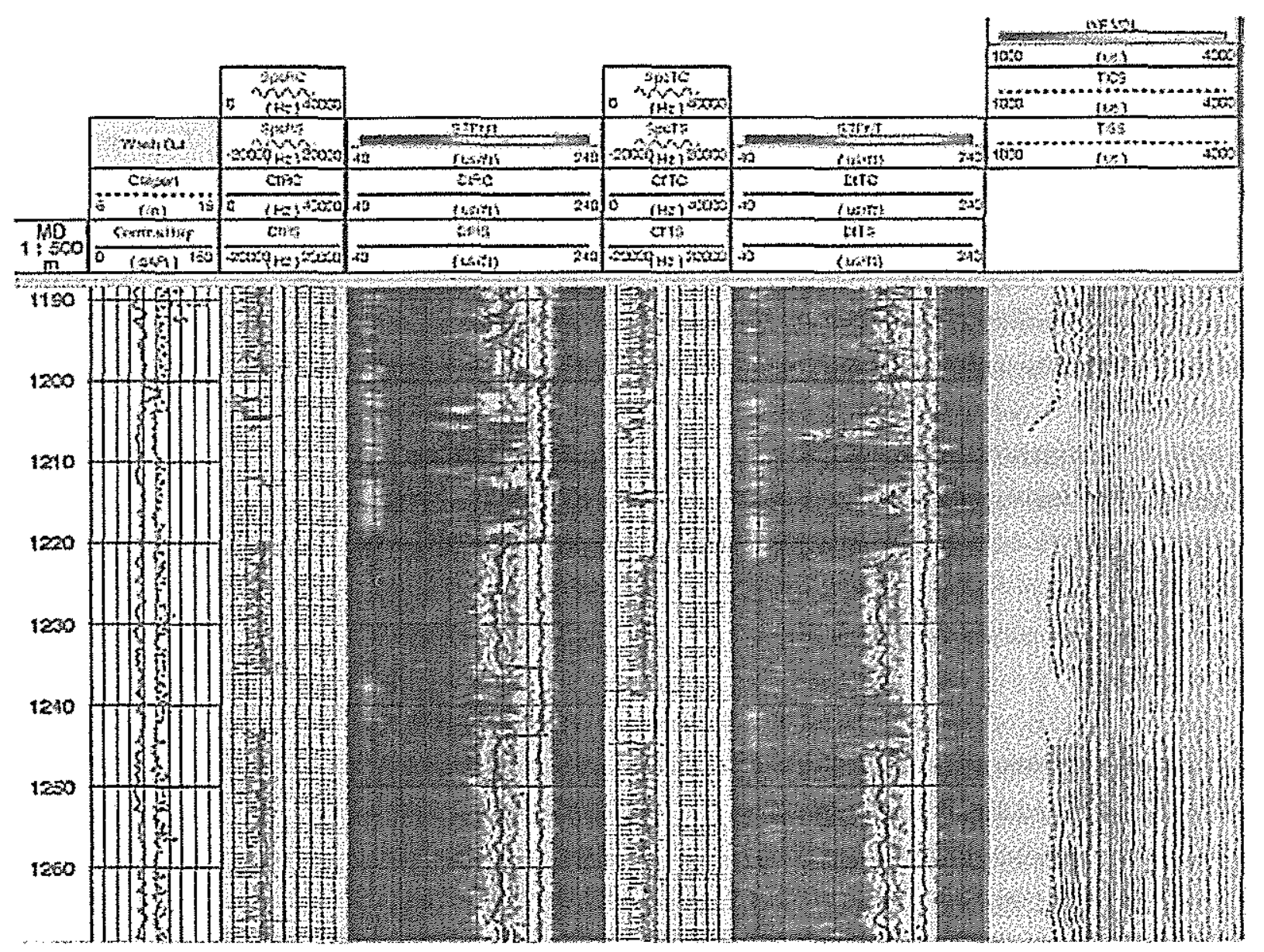

Fig. 1 Slowness-time-coherence log from DSI monopole mode ( From Takayama et al., 2004 ). 


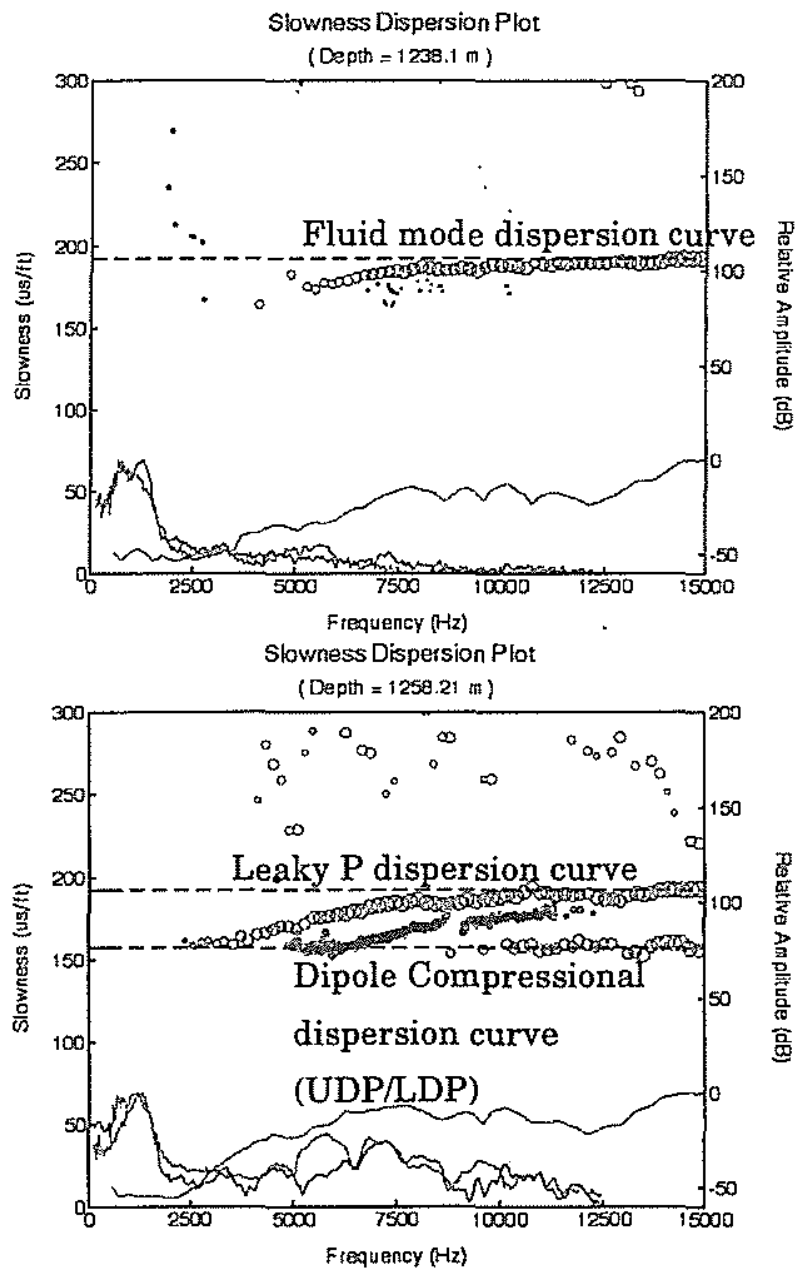

Fig. 2 Dispersion curves and amplitude spectrum( From Takayama et al., 2004 ).

The upper plot in the gas-bearing formation, and the lower plot at below the gas-bearing formation. Input data for calculating dispersion curves are eight traces in Figure 4 for Monopole P\&S (green circles and lines) and dipole mode data. The brown line denotes the mud slowness and the green line is the P-wave-slowness derived by the semblance processing. The lines in the lower part of the plot are the amplitude spectrum. The comparison of two dispersion plots highlight the non-existence of P-head-wave and dipole compressional wave in the waveform acquired in the gas-bearing formation.



Fig. 3 Inverted velocity curve from VSP direct travel times( From Takayama et al., 2004 ).

Tracks show from left to right and up to down the natural gamma ray (GR), deep-reading electrical resistivity (HLLD), inverted velocity curve from VSP direct travel times (Vp from VSP TT), and velocity from sonic $\log (\mathrm{Vp}$ from Sonic $\log$ ). 


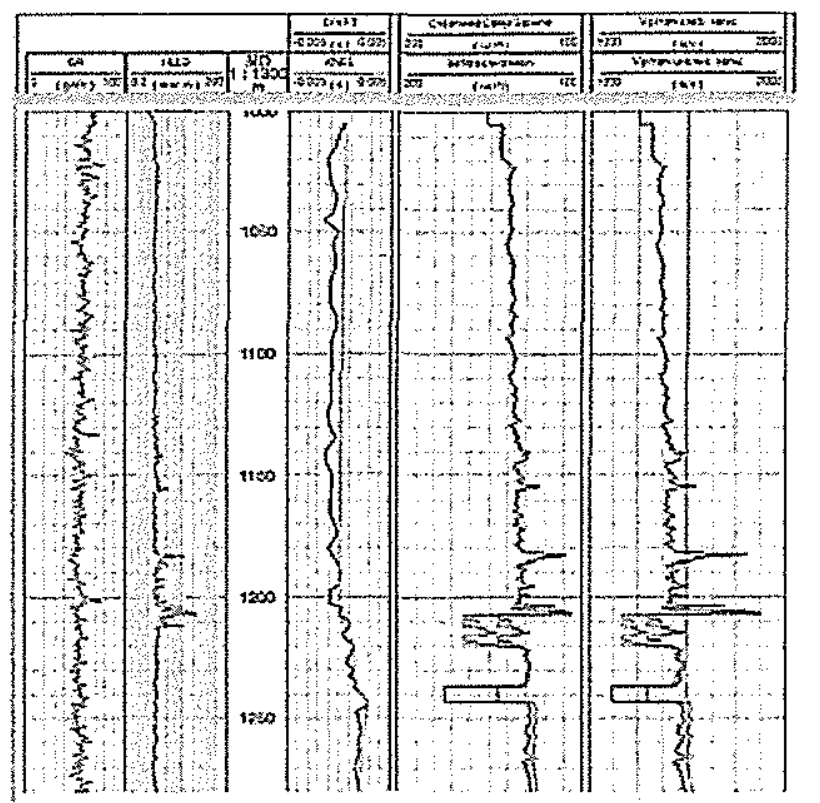

Fig. 4 Original sonic slowness and calibrated with VSP( From Takayama et al., 2004 ).

Tracks show from left to right and up and down the natural gamma ray (GR), deep-reading electrical resistivity (HLLD), drift curve (DRIFT, KNEE), sonic slowness calibrated with VSP (Calibrated Comp Slowne), original sonic slowness (before calibration), sonic velocity calibrated with VSP (Vp from calib. sonic), and original sonic velocity ( $\mathrm{Vp}$ from uncalib. sonic).

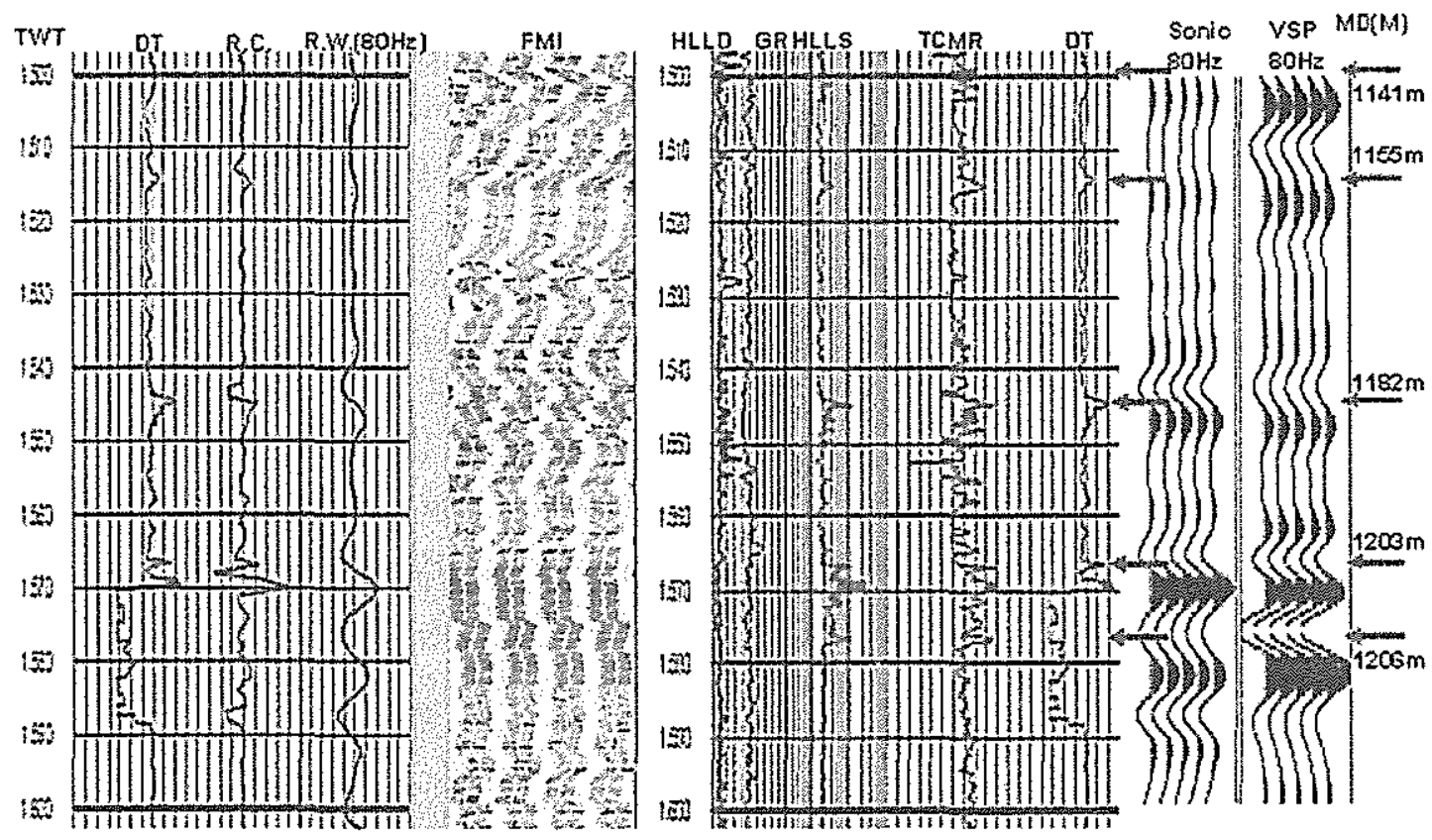

Fig. 5 Correlation of methane-hydrate-bearing formation, log-responses, synthetic seismogram, and VSP( From Takayama et al., 2004 ).

Tracks show from left to right the two-way time (TWT), calibrated sonic curve (DT), reflection coefficient (R.C.), convolved with $80 \mathrm{~Hz}$ Ricker wavelet (R.W.(80Hz)), FMI image (FMI), deep-reading electrical resistivity (HLLD), natural gamma ray (GR), shallow-reading electrical resistivity (HLLS), NMR total porosity (TCMR), synthetic seismogram from sonic with $80 \mathrm{~Hz}$ Ricker wavelet (Sonic $80 \mathrm{~Hz}$ ), and VSP corridor stack with $80 \mathrm{~Hz}$ Ricker wavelet (VSP $80 \mathrm{~Hz}$ ). The arrows indicate the depth of upper boundaries of methane-hydrate-bearing formation in depth scale. Methane-hydrate-bearing formation is characterized by red color in FMI image. 